\title{
Challenges for science in India
}

\author{
Although India can capitalize on a long history of scientific excellence, progress in scientific research \\ and science education needs to be implemented across all layers of society.
}

With a population of 1.15 billion, India is the largest democracy in the world. Its 2008 economic growth rate of $7.8 \%$ almost matches that of China, and seems robust despite the present recession. Research expenditure is increasing at a similar rate, and currently stands at about $0.9 \%$ of GDP.

At the same time, stark economic contrasts are evident even to the casual observer. A few stone throws away from some of the country's elite scientific institutions are scenes of poverty. According to World Bank figures, roughly $42 \%$ of the population - about 450 million people live on less than US\$1.25 disposable income a day ${ }^{1}$. On the other hand, around 20\% in the country are reasonably well off, with access to modern technology such as mobile phones ${ }^{2,3}$; in absolute numbers this means more than 200 million people, which is comparable to the population of Western Europe.

Despite this impressive economic growth, scientific research continues to lag behind the country's possibilities. Interviewed in this issue (page 362), the Secretary of State at India's Department of Science and Technology, T. Ramasami, indeed acknowledged a development gap with developed countries ${ }^{4}$.

Certainly, one problem is the comparatively low level of overall research investment - the present $0.9 \%$ in GDP is notably less than China's $1.5 \%$ or the $2.6 \%$ of the US. This value must increase if the country is serious about closing the gaps with leading nations. Insufficient scientific research in India's private sector seems to be part of the problem. The large pharmaceutical sector, for example, remains dominated by the fabrication of generic products rather than original formulations.

At present, a large section of the country's public research is concentrated in national research centres such as the S. N. Bose Center, the Raman Research Institute and organizations such as the Indian Association for the Cultivation of Science. In comparison, research at universities has been neglected. As detailed by Ramasami, in response to this problem the country has now launched a larger initiative that, for example, foresees

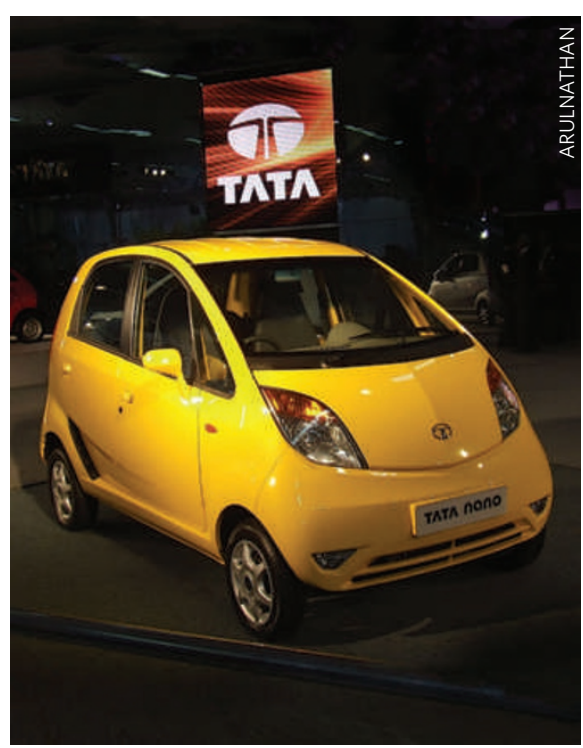

A global success story from India? The Tata Nano car was developed using the specific experiences and requirements of the Indian market.

extra funds for 14 elite universities.

Speaking to Nature Materials, however, a Vice-Chancellor of one of those fourteen universities emphasized that such initiatives are likely to remain insufficient to significantly improve the quality of their research and teaching.

It is not only in terms of research where India's universities are left behind. Its multifaceted higher education structure includes thirteen elite Indian Institutes of Technology (IIT), and their more recent spin-offs, the Institutes of Information Technology. Through their centralized entrance exams the IITs enforce tough selection, and their students are educated to a very high standard. However, to be able to lift a population of 450 million out of poverty and to have them participate in the country's economic development, higher education needs to be a priority. This is where well-functioning and well-funded universities could have an increasingly important role.

At the same time, India is already building on existing strengths, and is engaged in its own unique strategy to expand higher education. Rather than following a path like China has, where a foundation of economic strength was built on a large manufacturing sector, it seems that India is leapfrogging this lowwage phase of economic development by attempting to base its progress on a highly skilled workforce. And example of this is India's large service sector. In 2006 a series of new universities were announced and are currently under construction. These Indian Institutes of Science Education and Research (IISER) follow the concept of the successful IITs, but to further boost higher education, offer an integrated five-year masters programme across all disciplines of natural sciences ${ }^{5}$. The expectation is that this interdisciplinary approach will foster research that is increasingly crossing the boundaries between traditional disciplines, such as nanotechnology, energy or biotechnology.

It is modern concepts like these that may benefit India's scientific landscape most. Indeed, India has to capitalize on its own strength and experiences. Innovations borne out of this tradition may then lead to entirely new advances. A good example may come from an entirely different sector. In March the Indian automobile manufacturer Tata started selling its latest product, Tata Nano (Fig. 1). Its unique compact features combined with a very low price tag make the car not only ideally suited for India's domestic market, but also for international markets particularly in urban areas.

Science in India still has significant potential for further development. Although scientists from the subcontinent excel on an international level, the huge potential offered by the country's young population is far from being fully leveraged. Yet, India has a long and proud tradition of scientific excellence. As economic development advances and a broader section of society benefits from high-quality education, science in India will be able to fully capitalize on this unique heritage.

\footnotetext{
References

1. http://go.worldbank.org/DQKD6WV4T0

2. http://www.unicef.org/infobycountry/ india_india_statistics.htm

3. http://go.worldbank.org/V2IAJC8V50

4. Nature Mater. 8, 362-363 (2009).

5. http://www.iiserkol.ac.in/
} 